\title{
太湖地区西苔溪流域营养盐污染 负荷结构分析*
}

\author{
李恒鹏 刘晓玫 杨桂山
}

(中国科学院南京地理与湖泊研究所,南京 210008)

\begin{abstract}
提 要 污染负荷研究是实施污染物总量控制、保护水质的基础, 由于非点源污染一直是 水环境研究的一个难题, 致使河流污染负荷估算缺乏合理的估算方法. 本项研究针对太湖的富 营养化问题，选取太湖上游西苔溪流域，采用 GIS 的流域分析方法，选取单一土地利用类型的 小流域，分析流域土地类型与径流量及流域出口浓度的统计关系，获取不同土地利用类型营养 盐污染的产出率，合理估算了西莒溪流域的非点源营养盐污染负荷，并根据西苕溪流域社会经 济统计数据及已有的污染产出率研究成果，估算了西荢溪的点源营养盐污染负荷，在此基础上 估算了西荢溪流域的营养盐污染总负荷量, 分析了不同污染源在总负荷量的比例. 最后通过比 较估算的总负荷量与实测负荷量, 计算了西苔溪流域河网体系对营养盐的降解能力. 研究得出, 林地产出径流浓度总氮 $0.715 \mathrm{mg} / \mathrm{L}$ 、总磷 $0.039 \mathrm{mg} / \mathrm{L}$, 耕地产出径流浓度总氮为 $2.092 \mathrm{mg} / \mathrm{L}$, 总磷 $0.166 \mathrm{mg} / \mathrm{L}$, 西苔溪流域总氮负荷量为 $3143.43 \mathrm{t} / \mathrm{a}$ ，非点源污染负荷量为 $1589.52 \mathrm{t} / \mathrm{a}$; 总 磷负荷量为 $226.32 \mathrm{t} / \mathrm{a}$, 非点源为 $108.36 \mathrm{t} / \mathrm{a}$ ，西苦溪流域河网体系对总氮、总磷的年降解率分 别为 $35.39 \% 、 21.48 \%$.
\end{abstract}

关键词 太湖 流域 西苔溪 污染负荷 营养盐

分类号

\section{1 引言}

太湖流域是我国经济最为发达，城市化水平最高的地区之一，以仅占全国的 $0.4 \%$ 的 土地利用面积提供了 $10 \%$ 的国内生产总值[1]. 人类高强度的开发导致大量污染物和 N、P 等营养盐排放进入河湖水体，流域水环境污染日益加剧，自 20 世纪 60 年代以来，太湖每 十年下降一个等级，全流域 $80 \%$ 的河流水质达不到国家规定的地面 III 类水标准[2]. 1998 年低，国务院会同环湖的上海、江苏和浙江二省一市政府实施了以工业点源污染达标排放 为核心的“零点行动”方案，工业点源污染得到有效的控制，但因非点源污染没有得到控制， 水环境问题并没有真正得到解决 [3,4]。目前，流域管理部门及水环境研究学者普遍提出水环 境管理需要采用达标排放和总量控制相结合的管理方法[5-7]. 污染负荷估算是确定控制总 量的基础，但因非点源污染分布广泛、机理复杂至今仍缺乏合理的负荷估算方法 [8]，导致

\footnotetext{
* 国家自然科学基金项目 (40371111) 、中国科学院知识创新项目(CXNIGLAS-A02-013)和所长专项项目联合资助. 2003-08-07 收稿,2004-09-10 收修改稿. 李恒鹏,男,1973 年生, 副研究员, 博士.
} 
总量控制实施指标缺乏科学依据. 一些学者通过小区监测、人工降雨等方法对农田氮、磷

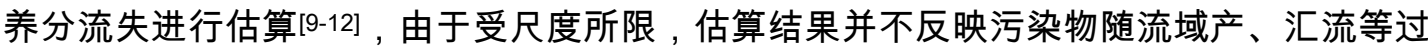
程的最终输出，在水环境管理应用中存在很大的不确定性. 同时因不能合理估算非点源污 染, 也使污染源与河流水质无法建立合理的定量关系. 本项研究针对太湖富营养化这一环 境问题，选取太湖上游西芳溪流域，应用流域分析方法，通过选取以单一土地利用为主的 小流域，分析流域土地利用与径流、营养盐浓度的统计关系，计算不同土地利用的营养盐 污染产出率，应用 GIS 方法建立流域尺度的非点源污染估算模型，并结合工业点源估算， 分析西苔溪流域的总负荷量和负荷结构，并在此基础上估算流域河网体系对营养盐污染的 降解率, 为太湖流域水污染总量控制提供技术支持及重要参数.

\section{2 研究区概况}

西苦溪流域位于太湖上游地区的浙西水利分区，属山区水系，面积为 $2267 \mathrm{~km}^{2}$. 流域 地势西南高东北低，依次呈山地、丘陵、平原的梯度分布，形成三面环山、中间凹陷、东 北开口的箕箕形辐射地形，地面高程在 2-1578m 之间. 流域属亚热带季风气候区，多年平 均降雨量为 $1465.8 \mathrm{~mm}$ ，但时空分布差异较大，汛期 (4-10 月) 的降水量占全年的 $75 \%$ 左右，降水一般随海拔高度上升而增加，平原地区多年平均降水量 $1333.5 \mathrm{~mm}$ ，中部丘陵 区多年平均降水量 $1459.6 \mathrm{~mm}$, 南部山区多年平均降水量 $1645.3 \mathrm{~mm}$. 西苔溪河长约 $143 \mathrm{~km}$, 源于天目山脉，向北流于湖州市杭长桥与东苔溪汇合入湖，是太湖的重要水源之 一，流域上中游河网为自然河网，下游地区为平原河网，受人工渠及其它水利工程影响较 大，水质以 III 类水为主. 土地利用主要为林地、耕地、居民地、果园、草地和水体，其中 林地占 $62.41 \%$, 耕地占 $29.73 \%$, 建筑用地占 $1.89 \%$. 西莒溪流域行政区划以安吉县域为 主, 包括安吉县全部和部分长兴与湖州市地区，共 26 个乡镇，其中安吉县 18 个，长兴县 2 个、湖州市区 6 个, 2000 年全流域人口 57.6 万，国内生产总值为 78.5 亿元，第一、二、 三产业国内生产总值的比例分别为 $17.1 \% 、 55.2 \%$ 和 $27.7 \%$. 本项研究所指的西莒溪流域 主要是西苔溪流域的上游和中游部分, 如图 1 所示, 主要考虑到以下几个方面的因素, 一 是下游地区东西苔溪汇合，河流水质并不完全反映西苔溪流域的特征; 二是西苔溪下游河 段建立防洪工程后，堤坝阻止了两岸地区自然汇水过程，同时下游河网通过人工渠连接， 由闸坝进行人为控制，改变了河网的自然特征，不能保证研究区的相对独立性. 三是选取 西苕溪流域上、中游地区和安吉县边界基本保持一致，有利于将以行政区统计的点源污染 和自然流域实现很好的统一, 分析点源污染及非点源污染在总污染负荷的比重.

\section{3 分析方法及过程}

\section{1 资料收集与分析方法}

研究采用 1:5 万地形图构建西莒溪流域数字地形，降 水和流量测站采用 30 年( 1959-1989)水文监测平均数据， 水质监测数据采用湖州市环境保护监测站 1999 年的年平 均数据，年内采样时间分平、丰、枯三期，每期采样两次， 选取的污染监测指标有总氮和总磷. 土地

利用采用 2000 年 TM/ETM 目视解译数据. 社会经济统计

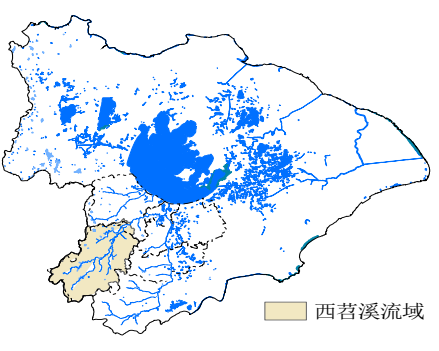

图 1 研究区位置

Fig.1 The location of study area 
资料采用 1999 年安吉县统计年鉴数据.

本项研究基于土地利用类型与径流量及径流营养盐浓度的定量关系估算非点源污染 负荷. 为建立流域尺度的土地利用类型与径流及营养盐浓度的关系，需要选取单一土地利 用类型的小流域. 小流域主要在西苦溪及临近区域选取, 主要因为统计分析需要较多的样 本，西芳溪及周边地区都为丘陵平原地区，地理环境具有相似性. 流域划分采用 Arcgis 的 水文分析模块 Archydro，以流量监测站和水质监测点为流域出水口，划分西苔溪及临近地 区的小流域边界. 流域降水量空间分布采用泰森多边形插值方法，土地利用由 TM/ETM 影 像目视解译获取. 将小流域边界和土地利用图及降水量分布图进行叠加分析, 分别获取各 小流域的土地利用结构，降水量，径流量及污染物浓度，建立不同土地利用类型与径流量 及污染物浓度的统计关系. 利用 GIS 的地图运算功能，建立西莒溪流域水文及非点源污染 估算模型，估算西苔溪流域的非点源营养盐污染负荷量. 点源污染包括工业污染及生活污 水集中排放部分，农业地区生活污水一般不直接排入河道，而是将人粪尿作为肥料施放到 农田, 转为非点源污染, 由于在估算非点源污染时以流域为基本单元，包括了这一部分， 因此点源污染的生活污水主要为城镇人口的生活污水排方，工业点源污染主要根据行业的 污染物产出率来估算. 利用以上方法分别估算西荢溪流域的非点源污染及点源污染，两者 相加即为该区的污染总负荷. 总污染负荷与流域出口实测污染负荷比较可以计算河网体系 的降解能力, 分析流程如图 2 所示.

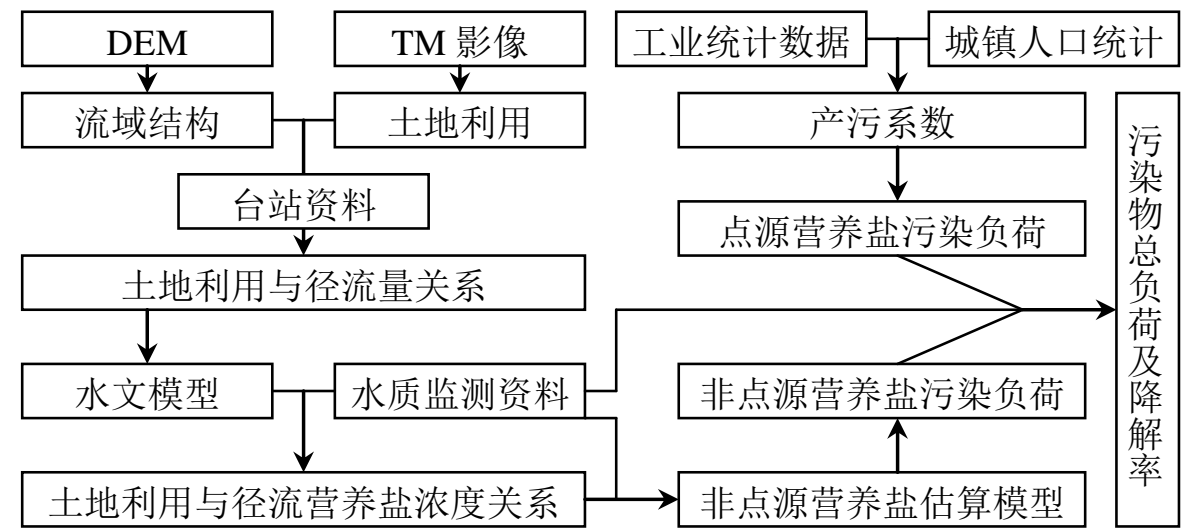

图 2 西苕溪流域营养盐污染负荷估算流程图

Fig.2 Schematic diagram of pollution load assessment in Xitiaoxi Watershed

\section{2 土地利用类型与径流及污染物浓度的关系}

为分析土地利用和径流、污染物浓度的关系，以西莒溪及周边地区上游流量监测点、 水质监测点为子流域出水口, 基于 $30 \mathrm{~m}$ 网格的数字地形划分小流域, 共获得 9 个上游小流 域的边界，小流域面积一般为 100-300 $\mathrm{km}^{2}$ (夹浦和乌龟山子流域除外), 将流量监测站为 出水口小流域与水文年鉴的流域面积进行比较, 误差范围在 $2 \%$ 以内, 监测小流域分布如 图 3 所示. 将小流域边界与土地利用分布图进行叠加分析，获取各监测流域的土地利用组 成结构，如表 1 所示，各小流域都以林地和耕地为主，两者面积之和占子流域总面积的 $95 \%$ 
左右，流域居民地面积一般都不超过 $2 \mathrm{~km}^{2}$ ，在小 流域中无大的城镇分布，一般都为零散分布的居民 点, 工业生产较少, 所以可以认为流域径流的水质 特征代表非点源污染的影响.

3.2.1 土地利用类型与径流的关系 径流是非点 源污染物输移的媒介，计算径流是估算非点源污染 物产出的前提. 本项研究采用多元回归模型建立径 流与降水和土地利用的定量关系. 降水和径流为 30 年的平均数据，选取以流量监测站为出水口的 6 个子流域，将流域边界与降水量分布 GRID 图进行 叠加, 获取各子流域的平均降水量, 径流量可以通 过流量监测数据与子流域面积相除获取，换算为统 一的单位，土地利用采用单一土地利用类型在子流 域面积所占的百分数, 由于各子流域耕地和林地占 到子流域总面积的 $90 \%$ 以上, 所以主要分析林地和 耕地对径流量的影响。

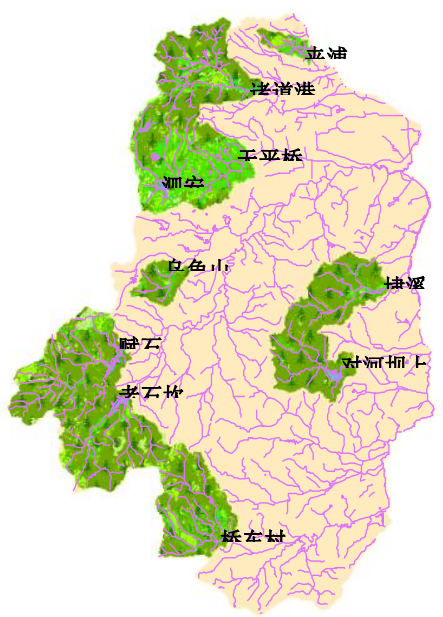

图 3 西苕溪及周边地区监测子流域空间分布 Fig.3 The distribution of monitoring subwatersheds

表 1 监测子流域的土地利用结构特征 单位: $\mathrm{km}^{2}$

Tab. The feature of monitoring subwatersheds

\begin{tabular}{cccccccc}
\hline 子流域 & 耕地 & 居民地 & 水体 & 林地 & 草地 & 园地 & 总面积 \\
\hline 桥东村 & 31.35 & 1.8 & 0.54 & 194.08 & 5.9 & 1.33 & 235.0 \\
对河坝上 & 11.45 & 0.74 & 3.62 & 145.52 & 0.54 & 0 & 161.89 \\
埭溪 & 27.12 & 1.1 & 0.41 & 136.59 & 0.55 & 0.28 & 166.05 \\
赋石 & 37.71 & 0.6 & 4.4 & 263.91 & 23.03 & 0.64 & 330.29 \\
老石坎 & 20.8 & 0.48 & 3.46 & 208.11 & 12.36 & 0.06 & 245.27 \\
诸道港 & 46.38 & 7.11 & 0.04 & 177.88 & 2.79 & 3.91 & 238.11 \\
天平桥 & 151.43 & 2.62 & 3.7 & 104.32 & 8.23 & 1.89 & 272.18 \\
夹浦 & 19.97 & 1.54 & 0.11 & 13.25 & 0.04 & 0.53 & 35.4 \\
乌龟山 & 11.94 & 0.06 & 0.29 & 48.37 & 0.00 & 0.00 & 60.7 \\
泗安 & 51.00 & 0.93 & 2.67 & 41.06 & 4.20 & 0.37 & 100.24 \\
\hline
\end{tabular}

回归方程选择参考相关领域的研究结果并比较不同回归方程的拟合效果，拟合的统计 关系如公式 (1)（2)，城镇建地在流域总面积占的比例较小，利用以上方法不能获得城 市用地与径流量的关系, 这里采用华东师范大学资源与环境学院周丽英等在徐汇区的研究 城市用地类型径流系数的结果，用公式 (3) 进行估算, 各土地利用类型与径流量的关系 如下:

$$
\begin{array}{ll}
Q=126.277 \times e^{0.00128 P} & (\text { 林地, 相关系数 : } 0.91, \text { 置信度 }>F: 0.026) \\
Q=64.0216 \times e^{0.00149 P} & (\text { 耕地, 相关系数 }: 0.91, \text { 置信度 }>F: 0.0249) \\
Q=0.6 \times P & \text { (建设用地, 径流系数约为 } 0.6 \text { ) }
\end{array}
$$


3.2.2 土地利用与径流营养盐浓度的关系 土地利用类型的非点源污染产出率是非点源 污染分析的重要参数，本项研究以径流污染物浓度标识土地利用面源污染产出率. 不同农 业土地利用类型的径流污染物浓度通过单一土地利用类型的小流域水质监测资料来估算. 林地非点源污染产出率采用对河口坝上子流域和老石坎子流域，这两个流域森林面积占 $80 \%$ 以上，耕地面积不到 $10 \%$ ，另外根据实地考察发现，约占 5\%左右的草地实际多分布 于山顶，属于自然草甸，而且分布有少数的林木，因此这两个子流域受人类活动最小，其 径流浓度可以代表林地面源污染产出率. 耕地污染物产出率采用夹浦、泗安和天平桥三个 子流域，耕地面积约占 50\%-60\%，其它土地利用类型为林地，可以用前面的林地污染物 产出率参数扣除林地的影响，扣除后的结果主要反映耕地的非点源污染产出率. 居民地及 水体所占土地利用面积较小，对评估结果影响不大，居民地参考匈牙利学者及国家环保局 南京环境科学研究所的有关研究结果来确定, 总氮为 $4.5 \mathrm{mg} / \mathrm{L}$, 总磷 $0.55 \mathrm{mg} / \mathrm{L}$; 水体因降雨 产生的面源污染通过降水监测结果来估算, 总氮为 $1.27 \mathrm{mg} / \mathrm{L}$, 总磷为 $0.025 \mathrm{mg} / \mathrm{L}$.

\section{3 流域非点源营养盐污染负荷估算}

应用前面有关土地利用与径流及污染物浓度的定量关系，采用 GIS 的空间分析与栅格 地图的图层代数运算，可以估算流域的农业非点源污染负荷. 计算公式如下：

$$
\text { Load }=\text { Runoff } \times \text { MRC } \times \text { Cellarea } \times \text { A }
$$

Load 为某一水环境指标的负荷量, Runoff 为根据降水深与土地利用关系计算的径流 深分布 Grid ,MRC(Mean Runoff Concentration)根据表 2 计算的流域径流污染物浓度分布 桶格图, Cellarea 为桶格格面积, $A$ 为单位换算系数.

表 2 不同土地利用类型径流营养盐平均浓度

Tab.2 Mean pollution concentration of runoff in forest land

\begin{tabular}{ccc}
\hline 土地利用类型 & $\mathrm{TN}(\mathrm{mg} / \mathrm{L})$ & $\mathrm{TP}(\mathrm{mg} / \mathrm{L})$ \\
\hline 林地 & 0.715 & 0.039 \\
耕地 & 2.092 & 0.166 \\
居民地 & 4.5 & 0.55 \\
水体 & 1.27 & 0.025 \\
\hline
\end{tabular}

考虑到草地和耕地、园地和林地下 垫面水力特性相差不大, 而且林地和耕 地面积占西荢溪流域总面积的 $90 \%$,其 他土地利用类型所占面积很小，所以将 土地利用图中的林地和园地，耕地和草 地进行归并. 作以上处理后，利用农业 土地利用类型和径流量的定量关系, 将 空间插值生成的降雨栅格图层带入到公

式(1)、(2)、(3)，在 Arcinfo 的 Grid 环境下计算出西苔溪流域径流深分布的栅格图层，然 后带入到公式 ( 4 ), 径流浓度棚格图由不同农业土地类型污染物产出参数及土地利用分布 图连接并栅格化生成, 所有计算栅格图均采用 $30 \mathrm{~m}$ 网格, 坐标采用 Albert 等面积投影, 计算结果如图 4 所示. 对面源污染空间分布栅格图进行统计分析得出西苕溪流域非点源营 养盐污染总氮为 $1589.52 t$, 总磷为 $108.36 \mathrm{t}$.

\section{4 流域点源污染营养盐负荷估算}

流域点源污染主要包括工业污染源和集中排放的生活污水，由于农村居民的生活污水 和人粪尿一般是分流的，以农业肥料的形式转变为非点源污染，城镇居民生活污水和人粪 尿绝对多数是合流的，因此，生活污水产生的营养盐点源污染主要为城镇居民生活污水的 点源污染. 工业营养盐点源污染及城镇居民生活污水污染可以通过社会经济统计数据及排 污系数计算. 国家环保局南京环境科学研究所 1997 年在太湖流域对包括研究区在内的 9 个市县 6 个主要污染行业的工业排污系数进行了估算，同时还通过大量样品测试分析生活 

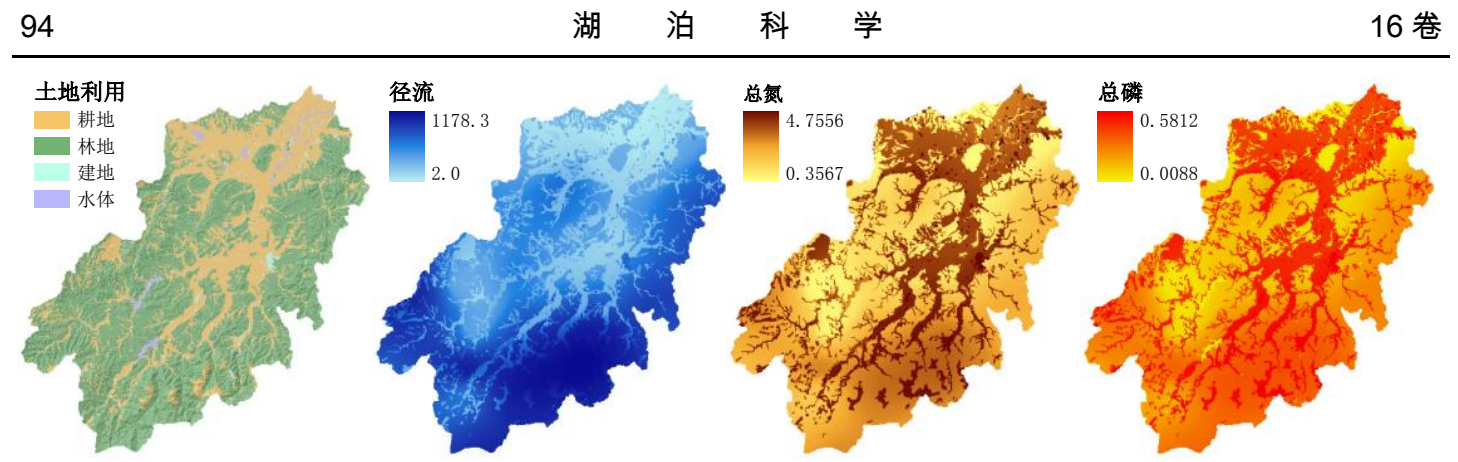

图 4 西苕溪流域非点源污染估算结果

Fig.4 The result of assessing the agriculture non-point pollution in Xitiaoxi watershed

污水的污染物产污率、处理率、净化率及最终的入河率. 本项研究估算西苔溪流域点源营 养盐污染负荷主要通过 1999 年安吉县社会经济统计数据和排污系数来估算，估算结果如 表 3、4 所示, 工业点源营养盐污染总氮为 1174.36t, 总磷为 83.07t, 生活污水营养盐污 染总氮为 $379.55 t$, 总磷为 $34.89 t$.

表 3 西苔溪流域工业点源营养盐污染负荷估算

Tab.3 The point pollution load from industry of Xitiaoxi watershed

\begin{tabular}{cccccc}
\hline 行 业 & $\begin{array}{c}\text { 产值 } \\
(\text { 万元 })\end{array}$ & $\begin{array}{c}\text { 排污系数 }- \text { 磷 } \\
(\mathrm{kg} / \text { 万元 })\end{array}$ & $\begin{array}{c}\text { 排污系数 }- \text { 氮 } \\
(\mathrm{kg} / \text { 万元 })\end{array}$ & $\begin{array}{c}\text { 总磷 } \\
(\mathrm{t} / \mathrm{a})\end{array}$ & $\begin{array}{c}\text { 总氮 } \\
(\mathrm{t} / \mathrm{a})\end{array}$ \\
\hline 纺 织 & 35874 & 0.39 & 1.69 & 13.99 & 60.63 \\
化 工 & 8016 & 0.2 & 10.8 & 1.60 & 86.57 \\
食 品 & 57186 & 0.86 & 16.87 & 49.18 & 964.73 \\
造 纸 & 10623 & 0.97 & 3.88 & 10.30 & 41.22 \\
医 药 & 1720 & 4.17 & 8.02 & 7.17 & 13.79 \\
皮 革 & 1827 & 0.45 & 4.06 & 0.82 & 7.42 \\
总 和 & 115246 & & & 83.07 & 1174.36 \\
\hline
\end{tabular}

表 4 西苔溪生活污水点源营养盐污染负荷估算

Tab.4 The point pollution load of living water from town

\begin{tabular}{lcccccccc}
\hline $\begin{array}{l}\text { 城镇人 } \\
\text { 口 }(\text { 人 })\end{array}$ & $\begin{array}{c}\text { 产污率-磷 } \\
(\mathrm{kg} /(\mathrm{a} \cdot \mathrm{h}))\end{array}$ & $\begin{array}{c}\text { 产污率-氮 } \\
(\mathrm{kg} /(\mathrm{a} \cdot \mathrm{h}))\end{array}$ & $\begin{array}{c}\text { 总磷 } \\
(\mathrm{t} / \mathrm{a})\end{array}$ & $\begin{array}{c}\text { 总氮 } \\
(\mathrm{t} / \mathrm{a})\end{array}$ & $\begin{array}{c}\text { 磷入河率 } \\
(\%)\end{array}$ & $\begin{array}{c}\text { 氮入河率 } \\
(\%)\end{array}$ & $\begin{array}{c}\text { 入河总磷 } \\
(\mathrm{t} / \mathrm{a})\end{array}$ & $\begin{array}{c}\text { 入河总氮 } \\
(\mathrm{t} / \mathrm{a})\end{array}$ \\
\hline 64725 & 0.74 & 8.84 & 47.90 & 572.17 & $72.9 \%$ & $66.3 \%$ & 34.89 & 379.55 \\
\hline
\end{tabular}

注 : 工业污染排污系数、生活污水产污率、入河率参考国家环保局南京环境科学研究所《太湖流域污染源调查及污染负荷分析 报告》的有关实验结果.

\section{5 流域营养盐污染总负荷量、结构及降解率}

基于点源污染和非点源污染分析可以估算西莒溪流域营养盐污染总负荷量及组成结 构，如图 5 所示，总氮负荷量为 3143.43t/a，其中点源为 1553.91t/a，占总负荷量的 49.4\%， 非点源污染负荷量为 $1589.52 \mathrm{t} / \mathrm{a}$ ，占总负荷的 $50.6 \%$; 总磷负荷量为 $226.32 \mathrm{t} / \mathrm{a}$ ，其中点 源为 117.96 , 占总负荷量的 $52.1 \%$ ，非点源为 $108.36 \mathrm{t} / \mathrm{a}$ ，占总负荷量的 $47.9 \%$. 对非点 源污染负荷中不同土地利用类型的贡献进行统计发现，研究区非点源污染主要来源与耕地 
和林地，占总面积 $31 \%$ 的耕地类型总氮、总磷分别贡献 $42.6 \%$ 和 $49.6 \%$ ，占总面积 $67 \%$ 的林地类型总氮、总磷分别贡献 $51.2 \%$ 和 $41 \%$ ，建地类型和水体类型各占总面积的 $1 \%$ ， 其中建地贡献的总氮、总磷分别为 $5.07 \%$ 和 $9.08 \%$ ，水体类型贡献的总氮、总磷分别为 $1.09 \%$ 和 $0.32 \%$. 点源污染中，工业总氮、总磷分别占 $75.6 \%$ 和 $70.4 \%$, 生活污水贡献总 氮、总磷分别为 $24.4 \%$ 和 29.6 .

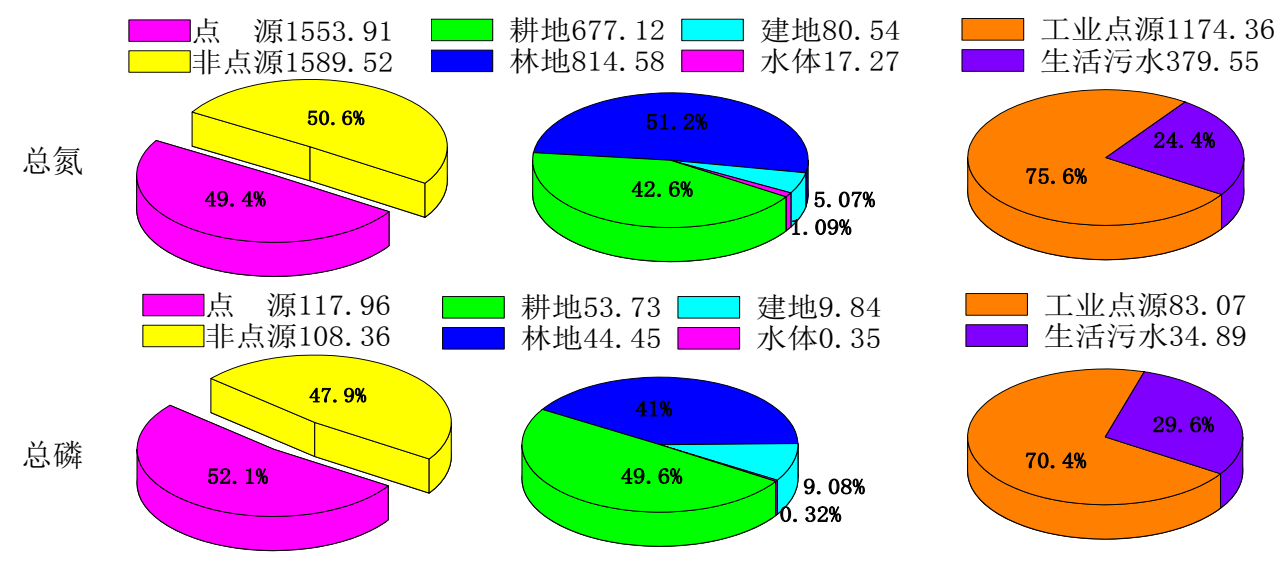

图 5 西苕溪流域污染负荷结构分析

Fig.5 The components of the Total $\mathrm{N}$ and P load in Xitiaoxi Watershed

以上负荷量估算为进入河流的营养盐负荷，事实上营养盐在河流输移的过程中，受物 理、化学及生物过程的影响会发生降解，将以上计算的总负荷量和实测的负荷量进行比较， 如果认为减少的部分为营养盐污染在河网中的降解部分，则可以初步估算营养盐污染在河 流网络中的年降解率. 实测流域出口荆湾监测点的总氮浓度为 $1.36 \mathrm{mg} / \mathrm{L}$ ，总磷浓度为 $0.119 \mathrm{mg} / \mathrm{L}$ ，由径流量可以估算实测总氮和总磷的年负荷量为 $2031.01 \mathrm{t} / \mathrm{a} 、 177.71 \mathrm{t} / \mathrm{a}$ ，则 总氮、总磷的年降解率分别为 $35.39 \% 、 21.48 \%$.

\section{4 结论}

综上所述可以得出以下结论：

不同土地利用类型的污染物产出率是估算非点源的基础，本文通过对单一土地利用类 型流域的水质监测对西苕溪流域主要土地利用类型林地和耕地产出径流浓度进行估算，林 地产出径流浓度总氮 $0.715 \mathrm{mg} / \mathrm{L}$ 、总磷 $0.039 \mathrm{mg} / \mathrm{L}$, 耕地产出径流浓度总氮为 $2.092 \mathrm{mg} / \mathrm{L}$ ， 总磷 $0.166 \mathrm{mg} / \mathrm{L}$.

西苕溪流域总氮负荷量为 3143.43t/a，其中点源为 1553.91t/a，非点源污染负荷量为 $1589.52 \mathrm{t} / \mathrm{a}$; 总磷负荷量为 226.32t/a，其中点源为 117.96t/a，非点源为 108.36t/a. 非点 源污染在污染负荷中占有较大的比重，超过工业点源污染和生活污水造成的点源污染，约 占总负荷量的 $50 \%$ 左右.

将西莒溪流域总负荷量估算结果与实测结果进行比较得出，流域河网体系对总氮、总 磷的年降解率分别为 $35.39 \% 、 21.48 \%$. 
参 考 文 献

1 关劲桥,黄贤金,刘红明等. 太湖流域水环境变化的货币化成本及环境治理政策实施效果分析一一江苏省为例. 湖泊科 学,2003,15(3): 275-279

2 林泽新. 太湖流域水环境变化及缘由分析. 湖泊科学,2002,14(2):111-116

3 范成新,季江,陈荷生. 太湖富营养化现状、趋势及综合整治对策.上海环境科学, 1997,16(8):4-7

4 黄文钰，杨桂山等. 太湖流域“零点”行动的环境效果分析. 湖泊科学,2002,14(1)：67-71

5 候晓梅. 我国总量控制政策的现状与适应性变革. 长江论坛,2003,(1):39-42

6 刘洁,冯银厂,朱坦. 总量控制在环境管理中的应用. 城市环境与城市生态,2003,16(1):59-61

7 王少平,俞立中,许世远等. 基于 GIS 的苏州河非点源污染的总量控制. 2002,22(6): 520-524

8 贺缠生,傅伯杰,陈利顶.非点源污染的管理及控制. 环境科学,1998,19(5):87-91

9 高超, 朱建国, 窦贻俭. 农业非点源污染对太湖水质的影响: 发展态势与研究重点. 长江流域资源与环 境, 2002,11(3):260-263

王宁,朱颜明,徐崇刚. GIS 用于流域径流污染物的量化研究. 东北师大学报自然科学版,2002,34(2): 92-98

黄满向,章申,唐以剑等. 模拟降雨条件下农田径流中氮的流失过程. 土壤与环境,2001,10(1):6-10

梁涛,张秀梅,章申等. 西苦溪流域不同土地类型下氮元素输移过程. 地理学报,2002,57(4): 389-396

\title{
Nutrient Pollutant Load Analysis of Xitiaoxi Watershed in Taihu Region
}

\author{
LI Hengpeng, LIU Xiaomei \& YANG Guishan
}

(Nanjing Institute of Geography \& Limnology, CAS, Nanjing 210008, P.R.China)

\begin{abstract}
The total pollutant load assessment is the key of water quality protection and total quantity control policy. Due to complicated mechanism of non-point pollution, there is lack of the effective methods to assess the non-point pollutant load, and the total pollutant load assessment are limited. This paper, aim at the eutrophication problem of Taihu lake, selects the sub-watersheds in Xitiaoxi watershed and nearby region with one landuse type mainly, analyze the relationship between landuse type and runoff concentration, and assess the nutrient pollutant load. Then, the point pollutant load is assess by the social-economic data and pollutant output rate of different industry type and living water. Based on the assessment of point and non-point pollutant load, the total nutrient pollutant and decay rate are calculated. According to the result of this study, the total nitrogen and phosphorus concentration of runoff from forest land are $0.715 \mathrm{mg} / \mathrm{l}$ and $0.039 \mathrm{mg} / \mathrm{l}$, from agriculture land $2.092 \mathrm{mg} / \mathrm{l}$ and $0.166 \mathrm{mg} / \mathrm{l}$, respectively. The total nitrogen load are 3143.43t/a in Xitiaoxi watershed, non-point nitrogen load is 1589.52t/a. The total phosphorus load are 226.32t/a and non-point phosphorus load is 108.36t/a. In Xitiaoxi river system, the annual decay rate of river network to total nitrogen load and phosphorus are $35.39 \%$ and $21.48 \%$, respectively.
\end{abstract}

Keywords: Taihu Region; Xitiaoxi Watershed; nutrient pollutant load 